\title{
AS TECNOLOGIAS DA INFORMAÇÃO E COMUNICAÇÃO NO ESTÁGIO SUPERVISIONADO DE LÍNGUA INGLESA: UMA REFLEXÃO NA FORMAÇÃO DE PROFESSORES
}

\author{
TECNOLOGÍAS DE INFORMACIÓN Y COMUNICACIÓN EN LA ETAPA \\ SUPERVISADA DE LENGUA INGLESA: UNA REFLEXIÓN EN LA \\ FORMACIÓN DE PROFESORES
}

\author{
INFORMATION AND COMMUNICATION TECHNOLOGIES IN THE \\ SUPERVISED ENGLISH LANGUAGE STAGE: A REFLECTION IN TEACHER \\ TRAINING
}

\author{
Rosalina Dantas da SILVA ${ }^{1}$ \\ Rafael Francisco Neves de SOUZA ${ }^{2}$ \\ Kellcia Rezende SOUZA ${ }^{3}$
}

RESUMO: Este artigo traz resultados de uma investigação a respeito da inserção de Tecnologias da Informação e Comunicação (TICs) no ensino e aprendizagem de Língua Inglesa para alunos do Ensino Fundamental, durante as aulas de Estágio Supervisionado ministradas por professores em formação regularmente matriculados no $3^{\circ}$ ano do Curso de Letras, habilitação em Língua Inglesa, de uma Instituição de Ensino Superior. Foi possível evidenciar que a maioria dos alunos considera importante o uso das TICs na ação pedagógica. No entanto, as ferramentas utilizadas ainda são muito convencionais e o potencial das atividades tecnológicas pouco explorado. Tal constatação evidencia as dicotomias entre o mundo analógico e digital que concorrem no contexto escolar contemporâneo.

PALAVRAS-CHAVE: TICs. Estágio supervisionado. Língua inglesa.

RESUMEN: Este artículo trae resultados de una investigación a respecto de la inserción de Tecnologías de la Información y Comunicación (TICs) en la enseñanza y aprendizaje de Lengua Inglesa para alumnos de Enseñanza Media, durante las clases de prácticas tuteladas ministradas por profesores en formación regularmente matriculados en el tercer año del curso de Letras, con habilitación en Lengua Inglesa de una institución de enseñanza superior. Fue posible evidenciar que la mayoría de los alumnos considera importante el uso de las TCIs en la acción pedagógica. Sin embargo, las herramientas utilizadas son aún muy convencionales y el potencial de las

\footnotetext{
${ }^{1}$ Universidade Federal da Grande Dourados (UFGD), Dourados - MS - Brasil. Mestre em Letras, Revisora de Textos na Editora da UFGD. ORCID: https://orcid.org/0000-0002-2866-6854. E-mail: rosalinasilva@ufgd.edu.br

${ }^{2}$ Universidade Estadual de Mato Grosso do Sul (UEMS), Dourados - MS - Brasil. Mestre em Letras, Professor Contratado do Magistério Superior - Departamento de Letras e Inglês e suas respectivas literaturas. ORCID: https://orcid.org/0000-0003-4354-3286. E-mail: urafasouza@ hotmail.com

${ }^{3}$ Universidade Federal da Grande Dourados (UFGD), Dourados - MS - Brasil. Doutora em Educação. Professora da Faculdade de Educação da UFGD. ORCID: https://orcid.org/0000-0002-8663-4615. Email: kellciasouza@ufgd.edu.br
} 
actividades tecnológicas poco explorado. Esa constatación evidencia las dicotomías entre el mundo analógico y digital que concurren en el contexto escolar contemporáneo.

PALABRAS CLAVE: TICs. Prácticas tuteladas. Lengua Inglesa.

ABSTRACT: This article presents the results of an investigation into the insertion of Information and Communication Technologies (ICTs) in the teaching and learning of the English language for elementary school students, during supervised internship classes taught by regular teachers enrolled in the 3rd year of Language Course, qualification in English Language of a Higher Education Institution. It was possible to evidence that most students consider the use of ICTs important in pedagogical action. However, the tools used are still very conventional and the potential of technological activities little explored. This finding highlights the dichotomies between the analog and digital worlds that compete in the contemporary school context.

KEYWORDS: TICs. Estágio supervisionado. Língua inglesa.

\section{Considerações iniciais}

Neste artigo buscamos relatar, a partir de práticas do Estágio Supervisionado, a inserção das Tecnologias da Informação e Comunicação (doravante TICs) nas aulas de Língua Inglesa. Afinal, é inegável o potencial das ferramentas tecnológicas no contexto de ensino-aprendizagem: "o mundo digital, as novas concepções de linguagem e as identidades constituídas e vividas na contingência diária fazem exigências inegociáveis sobre os atores em salas de aula" (BOHN, 2013, p. 95).

Trata-se de uma pesquisa bibliográfica e de campo, que tem como referência norteadora a abordagem qualitativa. Utilizamos como instrumento um questionário eletrônico para coletar os dados referentes às experiências didáticas de alunos, regularmente matriculados em uma instituição pública de Ensino Superior que cursam o terceiro ano do Curso de Letras, habilitação em Inglês.

Buscamos problematizar o uso das TICs como dispositivos capazes de garantir uma inovação pedagógica, sobretudo na disciplina de Língua Inglesa que ainda necessita de muito suporte educacional para se estabelecer no currículo escolar, bem como as TICs necessitam de discussão a respeito da sua inserção na formação de professores. Sob esse prisma, é importante pensarmos o papel dos docentes diante das demandas impostas pelo mundo globalizado. 


\section{Nas teias da teoria: uma reflexão acerca do uso das Tecnologias da Informação e Comunicação (TICs) no Estágio Supervisionado em Língua Inglesa}

Partindo do pressuposto de que a sala de aula é um espaço diverso e multifacetado, é importante destacar que o primeiro contato do professor em formação pode, muitas vezes, ser um lugar onde todo o seu acervo teórico estudado durante as aulas de estágio seja inexequível, pois além do contexto heterogêneo é preciso considerar todos os sujeitos sociais existentes na sala de aula e o potencial de intervenção existente.

O espaço, outrora visualizado enquanto aluno, agora exige o papel social de professor em formação, inserido na pluralidade cultural, linguística, social e, principalmente, tecnológica. Sendo essa última, uma das esferas que se relaciona com a produção deste artigo no âmbito educacional porque aponta a necessidade de reconhecer as mudanças presentes no ensino de línguas do mundo contemporâneo.

Como a escola vai lidar com a geração da web 2.0 que disponibiliza jogos, interações, exemplificações, traduções, que o professor mais competente jamais poderia sonhar em oferecer a seus alunos? Isto é especialmente verdade para o ensino e aprendizagem de línguas adicionais (BOHN, 2013, p. 93).

Dito isso, assumimos, portanto, a importância do professor de línguas na busca pelo aprimoramento da aplicação metodológica e prática de seus conteúdos, reconhecendo os adventos da tecnologia no universo didático. Ainda sobre isso, temos também o aluno que, por sua vez, é fruto de uma sociedade em constante processos de rupturas que o transforma em um indivíduo multifacetado. Quando se fala nesse sujeito, em constante processo de mudanças, é primordial ter em mente que diversos fatores influenciam na forma em que o homem constitui o mundo, e, consequentemente, na forma em que o aluno se define.

Stuart Hall defende a ideia de que foram os avanços científicos e tecnológicos trazidos pela modernidade que influenciaram diretamente essas mudanças radicais na maneira de viver no mundo e de enxergá-lo (HALL, 2003). A globalização e os avanços industriais, políticos, econômicos e tecnológicos mudaram de forma significativa as relações humanas, tendo em vista que a informação tornou-se muito mais acessível e rápida, influenciando assim, na forma como todo o sujeito pode se colocar em seus espaços, como por exemplo, a escola. Nesse sentido, a escola é vista como um lugar 
diverso, um núcleo em constante processo de mudanças, além de diferentes realidades sociais, que, influenciam, portanto, a miscigenação na sala de aula.

Sob uma ótica mais singular, é preciso pensar em como as relações com as TICs podem estar interligadas à questão de ensino de línguas, já que o contato inicial do professor em formação é pensado no paradigma de um novo sujeito (nesse caso o aluno) que é "afetado" com o advento da pós-modernidade. Ao professor em formação é delegada a preocupação de inovação das suas aulas em Língua Inglesa, em consonância com as mudanças das novas tecnologias e seus respectivos impactos fugindo, então, do conceito tradicional de como a sala de aula, geralmente, funciona.

Nesse panorama, o contato inicial do acadêmico de licenciatura com a sala de aula tem como gênese o Estágio Supervisionado, que abre a experiência das atividades do universo do mercado de trabalho, dando a oportunidade de relacionar à prática pedagógica, além de pensar na estrutura real de ensino e de como funciona o ambiente escolar.

Sobre o assunto, Sérgio Ifa (2006) aponta que:

A utilização dos recursos tecnológicos para alguns professores em formação pode ser entendida como o agente responsável por aulas mais ricas, o que demonstra que, para eles, a tecnologia, por si só, tem o poder de transformar aulas. Segundo reflexões dos professores em formação, há ênfase no papel do professor, abordando uma questão importante do letramento digital porque engloba discussões sobre: para quê, como e quando utilizar um recurso tecnológico para fins educacionais (IFA, 2006, p. 103).

Ainda sobre o tema, Ifa continua:

A introdução de uma ferramenta tecnológica em sala de aula para promover aulas mais dinâmicas, diferentes, interessantes e ricas pode desvelar muito da própria experiência escolar, do contínuo experiencial (Dewey, 1938) vividos pelos professores em formação como alunos, pois é, para muitos, a única experiência que ainda vivenciam. [...] A utilização de um elemento diferente - recurso tecnológico - empresta valor qualitativo à aula, transformando-a em um espaço que pode merecer a seguinte adjetivação: dinâmica, diferente, interessante e rica (IFA, 2006, p. 104).

Muito tem se dito sobre como pensar nas aulas de Língua Inglesa de uma forma que pudesse colocar a disciplina em um posicionamento mais equivalente, concreto e sério, ou seja, o descaso por essa matéria ainda é uma das preocupações dos estudiosos, pois a reconhecem como um "tapa buraco" no ensino público regular e muitas vezes no privado. Quando os professores em formação, participantes desse estudo, entraram em 
contato com a escola pública, notaram certa dificuldade de como os professores regulares de Língua Inglesa ministravam suas aulas - seja por questões estruturais da escola, dificuldade de aprendizagem dos alunos ou, até mesmo, falta de conhecimento de instrumentos de que pudessem colocar a disciplina numa esfera mais dinâmica e interessante.

Essa preocupação ainda gera determinada inquietação, sobretudo quando ponderamos a implementação do uso das TICs associada, inclusive, à necessidade de Alfabetização Midiática e Informacional (AMI) ainda emergente no Brasil, mas já consolidada em muitos outros países. Afinal, a prática pedagógica não pode ficar alheia a popularização das ferramentas Web 2.0, muito menos da crescente expansão das redes sociais.

Acrescentando nessa problemática o universo do ensino de línguas, é notória a importância do ato de observação do professor em formação durante seu período de estágio, para que sejam reconhecidas futuras mudanças e novas aplicações nas concepções do trabalho didático. A teoria e a prática são dois processos indispensáveis do Estágio Supervisionado, contudo ambos são completamente diferentes e precisam ser vivenciados, de acordo com as normas estabelecidas pela instituição escolhida. Muitos estudos exploram a questão da concepção do estágio, portanto Pimenta e Gonçalves (1990):

Consideram que a finalidade do estágio é propiciar ao aluno uma aproximação à realidade na qual atuará. E assim o estágio deixa de ser pensado como a parte prática do curso em formação e vira a parte de atividade teórica de conhecimento, fundamentação, diálogo e intervenção na realidade. (PIMENTA; GONÇALVES, 1990, p. 33).

O estágio é um elo de meditação da experiência vivida em sala de aula que deve ser valorizado com o mesmo prestígio do professor titular que o acadêmico acompanha. E a partir de toda a teoria e prática é importante que o acadêmico reflita a respeito da experiência adquirida no estágio para ser um bom profissional. Por esse prisma, é importante observar como são os meios usados pelo docente - no que se refere ao ensino de Língua Inglesa e como eles podem ser aplicados à luz das TICs. Barbosa destaca três métodos que são muito usados no ensino de Língua Inglesa, que embasam três movimentos importantes:

1. grammar-translation, que consiste no uso de tradução dos códigos linguísticos e uso gramatical; 
2. audiolingualism, refere-se às aplicações de áudio-orais e audiovisuais, somados à repetição de palavras e memorização e

3. natural or communicative approches, em quem o uso da fala e uma interação cultural oriunda da língua estudada são predominantes (BARBOSA, 2007, p. 36).

A primeira categoria, grammar-translation, é o método de ensino mais aplicado em muitas das escolas, pois, ainda existe uma concepção de senso-comum que, ensinar inglês é uma consequência limitada de apenas traduzir do português para o inglês (viceversa) ou se aprofundar no roteiro gramatical proposto para cada série. Sabe-se que o usuário adulto de uma língua domina todas as regras do sistema linguístico, pois "os princípios envolvidos na estruturação das sentenças de nossa língua são parte de nossa competência linguística" (SCHER; NEGRÃO; VIOTTI, 2004, p. 106).

É necessário que o professor saiba como manter um equilíbrio entre os conteúdos e suas metodologias aplicadas em sala, como por exemplo, saber a hora de se aprofundar em conceitos relacionados à gramática e tradução, assim como, compreender o momento mais dinâmico acerca de textos e do livro gramatical.

Ao pensar dessa maneira, há também, formas de introduzir o aluno no âmbito da TICs como - vídeos aulas, song activity, leitura, game, atividades multimídia colaborativas ou individuais e compreensão de textos por meio de materiais relacionados às novas tecnologias, sendo este posicionamento, uma ligação direta com as ideias de Barbosa (2007), em que a conexão com audiolingualism e natural or communicative approches podem ser aprofundadas de forma mais madura e coesa, pois ao usar textos, traduções e o livro gramatical, o professor pode encontrar formas concepções de informações e comunicações tecnológicas.

Para finalizar apontamos a importância de se pensar em aulas bem preparadas, pois, muito embora, o uso das TICs, venham a ser de extrema relevância para o processo de ensino e aprendizagem na sala de aula, quando não bem pensada e aplicada, podem causar problemas de coesão e coerência na estrutura didática da aula, passando assim, a impressão que a disciplina de Língua Inglesa cai nas brumas de uma matéria rasa e sem contribuição científico social. 


\section{Cenário da pesquisa: o contexto e a metodologia}

Esta pesquisa está inserida na área da Linguística Aplicada (LA), dada a preocupação com as questões relativas ao uso da linguagem em contextos específicos, que abrange aspectos tanto da formação do professor quanto do ensino-aprendizagem de língua. Quanto à característica indisciplinar, defendida por Moita Lopes (2009), é importante ressaltar que, conforme o autor, a LA é:

[...] é indisciplinar tanto no sentido de que reconhece a necessidade de não se constituir como disciplina, mas como uma área mestiça e nômade, e principalmente porque deseja ousar pensar de forma diferente, para além de paradigmas consagrados, que se mostram inúteis e que precisam ser desaprendidos, para compreender o mundo atual. Ou, como diz Stuart Hall [1996] em relação à teorização póscolonial: um modo de pensar que tem como objetivo atravessar/violar limites ou tentar "pensar nos limites" ou "para além dos limites". Uma que, talvez, seja mais bem entendida como transdisciplinar, no sentido de que deseja atravessar as fronteiras disciplinares, continuamente se transformando (MOITA LOPES, 2009, p. 20).

Diante do exposto, a opção pela LA justifica-se pelo fato desta pesquisa investigar a utilização de Tecnologias da Informação e Comunicação no ensino e aprendizagem da Língua Inglesa para alunos do Ensino Fundamental, durante aulas ministradas por professores em formação no Estágio Supervisionado de Língua Inglesa. A perspectiva desta pesquisa está centrada no estudo de caso e em um paradigma qualitativo, à medida que está apoiado, essencialmente, na interpretação dos significados contidos em um determinado contexto (BORTONI-RICARDO, 2008).

Participaram da pesquisa quatorze acadêmicos, de um universo de dezessete. No entanto, compõe o corpus desta pesquisa as respostas de somente dez professores em formação, equivalente àqueles que utilizaram pelo menos uma TIC no campo de estágio. Os participantes da pesquisa são estudantes regularmente matriculados no terceiro ano do curso de licenciatura em Letras, habilitação em Língua Inglesa e suas respectivas Literaturas, de uma Instituição Pública de Ensino Superior, localizada em Dourados, Mato Grosso do Sul. Esses alunos cumpriram carga horária de 62 horas/aula em escolas públicas localizadas no referido município.

Os dados utilizados são advindos das aulas ministradas pelos professores em formação que ocorreram nas séries que compõem a segunda etapa do Ensino Fundamental, a saber, do quinto ao nono ano, especificamente: um quinto ano, oito no sexto ano, um no sétimo, três no oitavo ano e um no nono ano, todos pertencentes ao 
turno diurno. Quanto às escolas, locus das aulas de Estágio Supervisionado, todas são pertencentes à rede pública de ensino, sendo nove municipais e cinco estaduais, são urbanas e estão localizadas em bairros distintos (centro e periferia) na cidade de Dourados-MS.

No que se refere à coleta de dados da pesquisa aplicada, foi utilizado um questionário semi-estruturado e online para que os alunos respondessem como estratégia de feedback da disciplina curricular de Estágio Supervisionado em Língua Inglesa, que possui carga horária de 68 horas/aula, com duração anual, ministradas no turno vespertino, uma vez na semana. Segundo os objetivos pedagógicos do curso, um dos objetivos de ensino da disciplina de Estágio Supervisionado em Língua Inglesa é integrar os diferentes aspectos de estudos da linguagem na esfera cultural, histórica e artística originárias de determinados grupos.

Ainda no contexto desta pesquisa é mister caracterizarmos o perfil do professor formador, partindo do pressuposto de que é necessário buscar compreender o saberensinar. Afinal, é importante reconhecer que os professores utilizam diferentes saberes provenientes de suas experiências profissionais, pessoais e, de modo geral, das suas relações com as diferentes organizações e agentes sociais (TARDIF, 2002).

O professor formador concluiu a graduação em Letras, habilitação Português/Inglês pela Universidade Estadual do Mato Grosso do Sul (UEMS) - campus de Dourados, em 2014. Concluiu o mestrado em Letras na Universidade Federal da Grande Dourados (UFGD) em 2017. Iniciou o exercício da profissão docente em 2015, atua em uma escola particular de ensino de línguas e ministra aulas de Estágio Supervisionado em Língua Inglesa em uma instituição pública de Ensino Superior, desde 2018.

Em sintonia com as pesquisas em LA, é importante pensar os sujeitos desta reflexão no contexto da formação de professores, o que significa reiterar o "entrelugar" (nos termos do Pós-Colonialismo) onde os professores em formação oscilam entre os papéis de professores e de alunos-estagiários, como apontado nas bases epistemológicas deste estudo. Os meandros dessa complexidade também atingem o professor formador no processo de meta-avaliação e nos limites do seu fazer pedagógico. 


\section{Análise da experiência com TICs nas aulas de Estágio Supervisionado em Língua Inglesa}

O questionário aplicado aos professores em formação não foi identificado para que os alunos se sentissem mais à vontade para contribuir. Houve quatorze respondentes da pesquisa, o que representa $82 \%$ de adesão considerando que há dezessete acadêmicos regularmente matriculados na disciplina de Estágio Supervisionado na turma pesquisada.

No intuito de investigar o quanto os livros didáticos (LD) influenciam as ações pedagógicas e planejamento das aulas, pesquisamos entre os entrevistados a utilização do LD na rotina escolar. Para esta questão, numa escala de 1 a 5 (em que 1 representa pouca utilização e 5 muito utilizado), aproximadamente, $86 \%$ assinalaram 1 e 2 enquanto apenas um respondente assinalou 3 e outro assinalou 5. O resultado médio de utilização do LD foi 1,71 nas turmas pesquisadas. Sendo assim, é possível concluir que o (não) uso das TICs não está diretamente relacionado a uma possível prescrição constante no material didático.

Utilizando o mesmo método e intervalo da questão anterior, solicitamos aos participantes que respondessem o quanto consideram importante o uso TICs no contexto educacional, no âmbito do ensino-aprendizagem de Língua Inglesa. A média foi de 4,35 , isto é, muito próxima de 5, critério que representa "muito importante". Essa avaliação dos alunos pode estar influenciada pelo aporte teórico-metodológico oferecido pelo professor formador durante a disciplina de Estágio Supervisionado.

A próxima pergunta separa em dois o grupo de respondentes à medida em que revela a (não) utilização de TICs durante as aulas de Estágio Supervisionado. Dos professores em formação que responderam $29 \%$ deles não utilizaram nenhuma TIC durante sua prática pedagógica, enquanto $71 \%$ dos alunos afirmaram a utilização de pelo menos uma TIC durante a aula. Dado os objetivos deste artigo, como já exposto nos aspectos metodológicos, faremos a análise somente daqueles professores em formação que utilizaram as TICs.

As TICs foram utilizadas basicamente para transpor materiais para o meio digital por meio de sistema multimídia, computador e caixas de som com a finalidade de exibir vídeos, slides e músicas. A inclusão das TICs permeando os conteúdos demonstra que os professores em formação estão criando oportunidades para momentos de educação tecnológica. No entanto, por meio da descrição das TICs utilizadas é possível notar uma atitude ainda muito tímida diante das novas tecnologias. 
Com o propósito de aprofundar esta questão, indagamos aos participantes da pesquisa qual foi a motivação para utilização das TICs na ação pedagógica, $70 \%$ afirmaram que houve interesse dos alunos para que as TICs foram inseridas no decorrer da aula. Esse dado nos faz refletir a respeito da necessidade digital que a geração Y impõe aos professores no contexto de ensino-aprendizagem da Língua Inglesa. Quanto à finalidade de utilização das TICs, os professores em formação utilizaram na transposição didática das habilidades já descritas neste artigo, fundamentadas por Barbosa (2007).

Para finalizar a análise de utilização das TICs, questionamos, no método em escala, em que medida os professores consideraram as TICs importantes para atingirem seus objetos de ensino. A média foi de 4,1 o que demonstra que a maioria dos participantes (nove) consideram relevante o uso das TICs. No entanto, cabe ressaltar que apenas um aluno avaliou a utilização das TICs como pouco importante (escala 1). $\mathrm{Na}$ verdade, essas respostas reiteram o papel social dos professores em formação, ou seja, enquanto sujeito imersos no universo tecnológico do mundo contemporâneo, mas que muitas vezes não exploram o potencial do mundo digital na sua ação pedagógica.

\section{Considerações finais}

Embora o objetivo do artigo tenha sido relatar a experiência da utilização das TICs nas aulas de Estágio Supervisionado, é importante salientar que é necessário um espaço formal na estrutura curricular das licenciaturas que aborde a inserção das TICs na prática pedagógica, sob o risco dos professores em formação estarem cada vez mais ilhados na tradição analógica que é tão distante dos anseios digitais do mundo contemporâneo. Isso significa que, mesmo diante das demandas impostas do mundo tecnológico, as licenciaturas ainda precisam incluir formalmente a discussão sobre as TICs na rotina escolar.

Compreende-se, portanto, que embora existam discussões acerca do processo de ensino de línguas, a utilização das TICs e funcionamento na disciplina de Língua Inglesa, ainda assim, encontra-se dificuldade na didatização dos conteúdos, pois existe uma internalização estruturalista de como ministrar essa disciplina, limitando assim, maneiras de ampliar a matéria de forma mais dinâmica e lúdica. Todavia, existe um 
grande estímulo nos adventos científicos onde possibilitam e agregam uma reflexão no espaço das TICs e como aplicá-las.

\section{REFERÊNCIAS}

BARBOSA, Ana Amáilia Tavares Bastos. O ensino de artes e de inglês: uma experiência interdisciplinar/ Ana Amália Tavares Bastos Barbosa. - São Paulo: Cortes, 2007.

BOHN, Hilário I. Ensino e aprendizagem de línguas: os atores da sala de aula e a necessidade de rupturas. In.: MOITA LOPES, L.P (Org.). Linguística Aplicada e a Modernidade Recente: Festschriff para Antonieta Celani. São Paulo: Parábola Editorial, 2013.

BORTONI-RICARDO, Stella Maris. O professor pesquisador: introdução à pesquisa qualitativa. São Paulo: Parábola Editorial, 2008.

HALL, S. A identidade cultural na pós-modernidade. Rio de Janeiro: DP\&A Editora, 2000.

MOITA LOPES, Luiz Paulo da. Da aplicação de linguística à linguística aplicada indisciplinar. In: PEREIRA, R. C.; ROCA, P. (Orgs.). Linguística aplicada: um caminho com diferentes acessos. São Paulo: Contexto, 2009.

IFA, Sérgio. A formação pré-serviço de professores de Língua Inglesa em uma sociedade em processo de digitalização. São Paulo: Pontifícia Universidade Católica de São Paulo, 2006.

MORAES, Márcia. Didática II. Rio de Janeiro: CCAA Editora, 2007.

NEGRÃO, Esmeralda; SCHER, Ana; VIOTTI, Evai. A competência linguística. In: FIORIN, J.L. et al. (Orgs.). Introdução à Linguística II: princípios da análise. 3 ed. São Paulo: Contexto, 2002. p. 95-119.

PIMENTA, Selma Garrido. Estágio: diferentes concepções. In: PIMENTA, Selma Garrido; LIMA, Maria Socorro Lucena. Estágio e docência. José Cerchi Fusari (rev. téc.) - São Paulo: Cortez, 2004.

TARDIF, Maurice. Saberes docentes e formação profissional. Petrópolis, RJ: Vozes, 2002. 


\section{Como referenciar este artigo}

SILVA, Rosalina Dantas da; SOUZA, Rafael Francisco Neves de; SOUZA, Kellcia Rezende. As Tecnologias da Informação e Comunicação no Estágio Supervisionado de Língua Inglesa: uma reflexão na formação de professores. Rev. EntreLínguas, Araraquara, v. 5, n. 2, p. 418-429, jul./dez. 2019. E-ISSN: 2447-3529. DOI: 10.29051/el.v5i2.12980

Submetido em: 18/04/2019

Revisões requeridas: 03/05/2019

Aprovado em: 15/05/2019

Publicado em: 01/10/2019 